\title{
ADHESIVE BRIDGES IN THE TREATMENT OF HYPODONTIA OF THE UPPER LATERAL INCISORS IN ADULTS: 12 YEARS OF CLINICAL OBSERVATIONS
}

\author{
Leopold Wagner, Barbara Rafałowicz \\ Department of Dental Propaedeutics and Prophylaxis, Medical University of Warsaw, Dentistry Division, Warsaw, Poland
}

\begin{abstract}
INTRODUCTION: Hypodontia of the upper lateral incisors can be treated with an implant-supported denture, fixed and removable denture, and orthodontic procedures. Due to fast effect of the treatment and relatively low cost, one of the possible therapeutic options is an adhesive bridge.

ОвјестіVEs: The aim of the study was to present the clinical effects of the use of adhesive bridges in the treatment of agenesis of the upper lateral incisors during 12 years of observation.

MATERIAL AND METHODS: The study included 13 adhesive bridges that were used in patients aged 18-30. The bridges were clinically and radiologically evaluated every 6 months in the first year of use, and then every year for a period of 12 years. In the 10th year of follow-up, patients participated in a survey measuring their satisfaction with the therapeutic method.

RESULTS: In the first 6 years, there was no aberration from the acceptable state in any case assessed. In the $7^{\text {th }}$ and $10^{\text {th }}$ year of observation, 2 fiber-reinforced composite bridges (FRC) were lost. Maryland bridges achieved a full clinical success after 12 years of use, despite slight color disharmony in relation to neighboring teeth and the necessity of re-cementing 1 bridge, while FRC bridges showed clinical efficiency of 55.55\%.

ConcLusions: The results obtained indicate that adhesive bridges can be used as long-term restoration in the treatment of hypodontia of the upper lateral incisors. The conditions determining their application are the absence of carious lesions of the abutment teeth, a large adhesive surface within the enamel, and particularly good oral hygiene.
\end{abstract}

KEY WORDS: clinical evaluation, hypodontia, survey research, adhesive bridges.

J Stoma 2020; 73, 3: 95-99

DOI: https://doi.org/10.5114/jos.2020.96757

\section{INTRODUCTION}

Modern dentistry has many methods of restoring congenital missing teeth in the anterior region, including implant-supported denture, fixed and removable dentures, adhesive bridges, and orthodontic space closure followed by dental recontouring [1-3].
According to many authors, the most recommended method involves the use of implant-supporting single crown, consisting of the insertion of intraosseous dental implant and the fitting of ceramic or metal-ceramic. crown. In the case of limited space, a mini implant may be used instead of the traditional one [4-6]. However, it should be noted that the single implantation in
JOURNAL OF STOMATOLOGY CZASOPISMO STOMATOLOGICZNE
AdDRESS FOR CORRESPONDENCE: Leopold Wagner, Department of Dental Propaedeutics and Prophylaxis, Medical University of Warsaw, Dentistry Division, 59 Nowogrodzka Str., 02-006 Warsaw, Poland, e-mail: leopold.wagner@wum.edu.pl

ReCEIVED: 19.05.2020 • ACCEPTED: 07.06.2020 • Published: 30.06.2020 
the aesthetic region in young patients can lead to serious complications. It has been proven that clinically significant vertical bone growth of the alveolar ridge occurs after the age of 20, especially in men. Too early implant placement in the region of upper lateral incisors may result in the formation of incisal line and an open bite at the implant site. The implant restoration does not follow the development of cranio-facial structures, which results in a higher implant position $[7,8]$.

A long-lasting positive effect of treatment is also obtained after the use of traditional three-unit bridges. However, the need for extensive preparation of abutment teeth was associated with significant loss of dental hard tissues and can irritate pulp tissue causing inflammation, which consequently increases the possibility of early or late post-operative complications $[9,10]$.

In situations, where local or general contraindications, patient reluctance to have the surgery performed or economic restrictions exist, other therapeutic methods should be considered. One of the solutions is the use of adhesive bridges, e.g. Rochette or Maryland [11-15]. These restorations based on a metal framework are characterized by high mechanical strength and good retention [12-14]. An alternative solution is the use of fiberreinforced composite bridges (FRC). They can be made by direct or indirect methods $[15,16]$. FRC bridges are considered minimally invasive restorations because they require only a little preparation of mineralized tissues. In some cases, the preparation may relate to previously made fillings, or even may not be needed if there is sufficient space for wing retainers [15]. In the treatment of hypodontia of the upper lateral incisors, zirconia ceramic cantilever resin-bonded fixed dental prostheses (RBFDPs) are also used [17]. It has been observed that they do not generate unfavorable stresses between the blocked spans of the abutment teeth, which occur during protrusive movements and laterotrusion in threeunit bridges [18]. The single-span bridge moves together with the abutment tooth.

\section{OBJECTIVES}

The aim of the study was to present the clinical effects of the use of adhesive bridges in the treatment of agenesis of the upper lateral incisors during 12 years of observation.

\section{MATERIAL AND METHODS}

The study included 4 Maryland and 9 FRC bridges that were used in 13 patients aged 18-30. They were one of 6 groups among 146 patients, who were under the treatment for hypodontia of the upper lateral incisors. Adhesive bridges were supposed to be used as temporary restorations before implantation. However, due to changes in patients' economic status, they were left as long-term restorations. All patients were generally healthy, with proper oral hygiene maintained and low risk of caries and did not require additional preventive procedures. Ten patients were previously treated orthodontically. The teeth surrounding the gap did not require preparation, or a small preparation was performed in the presence of existing fillings.

Maryland bridges were made in the technical laboratory of HEARENIUM PW alloy (Heraeus Kulzer $\mathrm{GmbH}$, Germany) and Vita Omega ceramic (Vita Zanhfabric, Germany). FRCs were made using the direct method of Herculite XRV Laboratory composite (Kerr Corp, USA) on a FibreKor fiberglass substructure (Pentron Clinical, USA). Maryland bridges were cemented using Panavia adhesive cement (Kuraray Dental, Japan).

The bridges were clinically and radiologically evaluated every 6 months in the first year of use, and then every year for a period of 12 years as well as in emergency situations. The California Dental Association (CDA) quality assessment system was applied for functional and aesthetic assessment, which was modified for the purposes of this study. A 4-grade assessment scale was adopted: A - acceptable, B - restoration requiring repair, $\mathrm{C}$ - re-making, D - loss of restoration and change of treatment method. The result of the treatment was considered acceptable if evaluated additions maintained their retention, marginal tightness, anatomical shape, surface color, and smoothness. Moreover, the condition of periodontal tissues, gums, and mucosa was adequate, and there were no pain, fractures, periapical changes, and symptoms of caries. The type and number of restoration damage and repairs performed were recorded in a patient's file.

In the $10^{\text {th }}$ year of follow-up, patients participated in a survey measuring their satisfaction with the therapeutic method used. The following questions were included in the survey: Are there any complications? Is the aesthetic effect satisfactory? Is the chewing efficiency correct? Is the phonetics correct? Have the repairs meet your expectations? Are you satisfied with follow-up visits? Would you change the therapeutic method used to treat the hypodontia of the upper lateral incisor? Each question had a 2-level, balanced Yes/No answer scale.

Excel Office 365 (Microsoft) was used to analyze the therapeutic effects obtained and survey data.

\section{RESULTS}

Figures 1-4 show selected adhesive bridges after adhesive fixing and after 12 years of usage. Figure 5 demonstrates the loss of the adhesive bridge, Figure 6 shows the delamination, and Figure 7 presents atrophy of bone tissue at the site of tooth agenesis 12 . The results of the assessment of effectiveness of adhesive bridges are presented in Figure 8.

Table 1 presents the results of patients' satisfaction survey 10 years after completing the additions. 


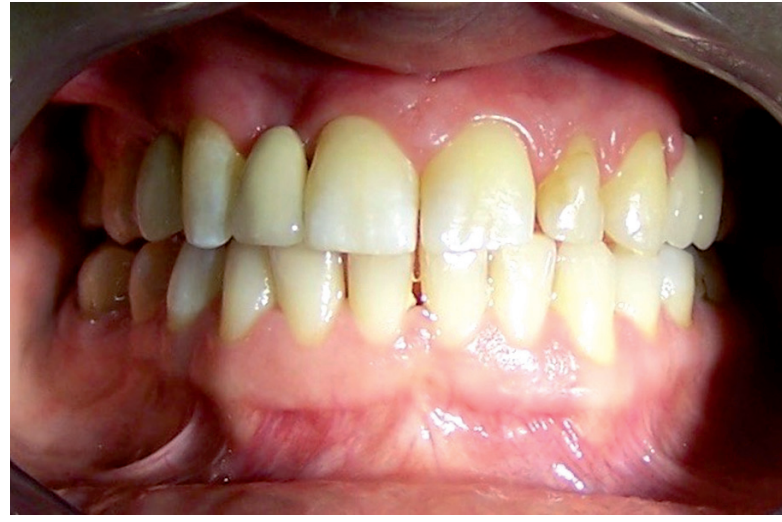

FIGURE 1. Patient B.S. Maryland bridge 12 after adhesive fixing

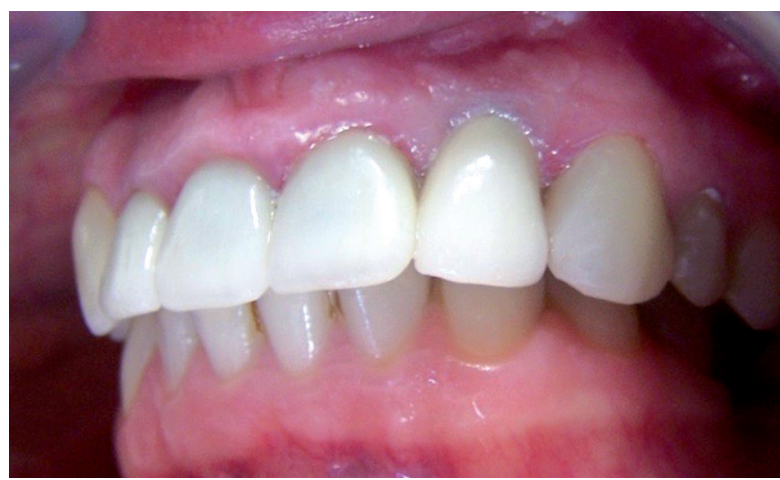

FIGURE 3. Patient M.P. FRC bridge 22

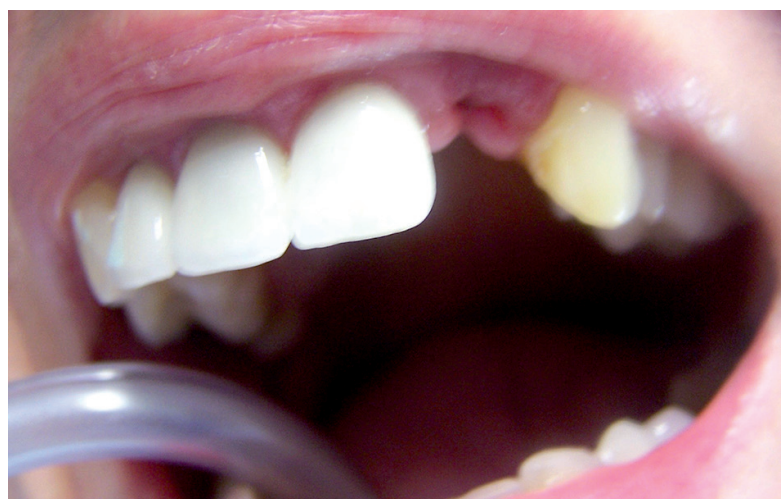

FIGURE 5. Patient M.P. Loss of FRC bridge 22

In the first 6 years, there were no aberration from the acceptable state (grade A) in any case assessed. In the $7^{\text {th }}$ year of observation, 2 FRC bridges lost their retention due to delamination and required re-making. In the $10^{\text {th }}$ year of follow-up, another 2 FRC bridges lost their retention, and patients decided to change the treatment method.

Maryland bridges achieved full clinical success after 12 years of usage, despite the slight color disharmony in relation to neighboring teeth and the necessity of re-cementing 1 bridge, while FRC bridges showed clinical efficiency of $55.55 \%$. The adhesive reconstruction made were highly rated by patients in terms of aesthetic, functional, and economic values.

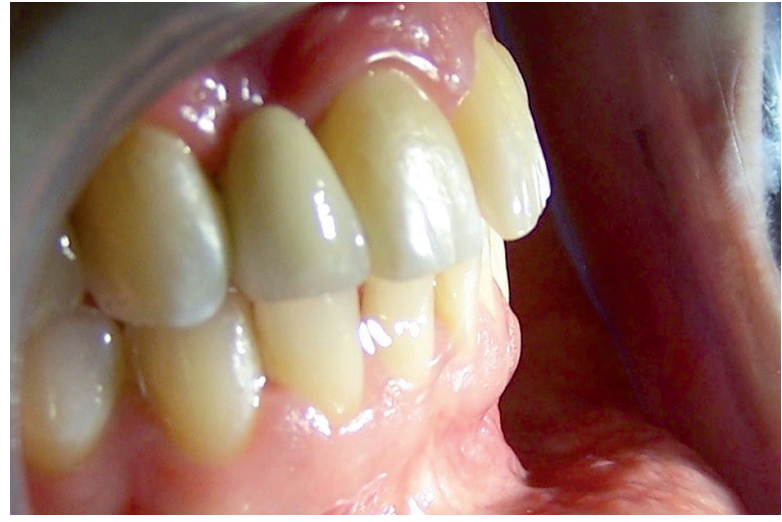

FIGURE 2. Patient B.S. State after 12 years

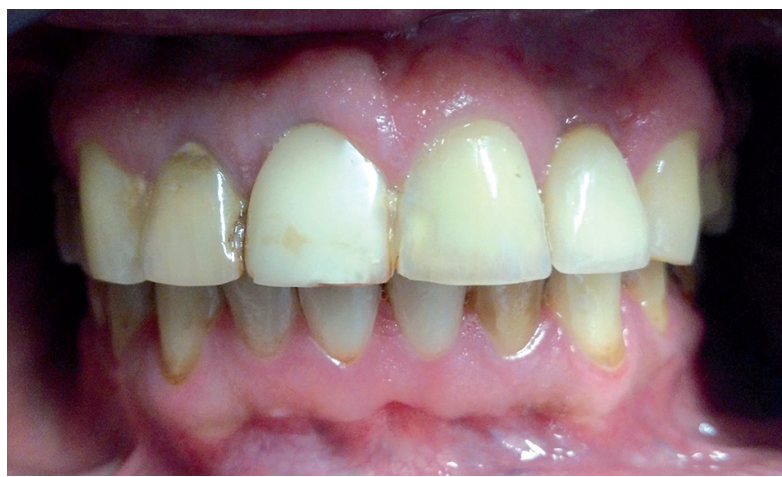

FIGURE 4. Patient M.P. State after 12 years

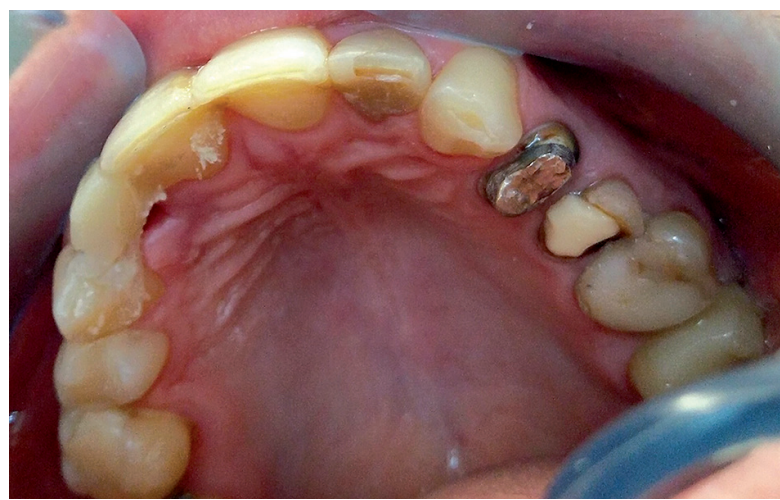

FIGURE 6. Visible FRC delamination

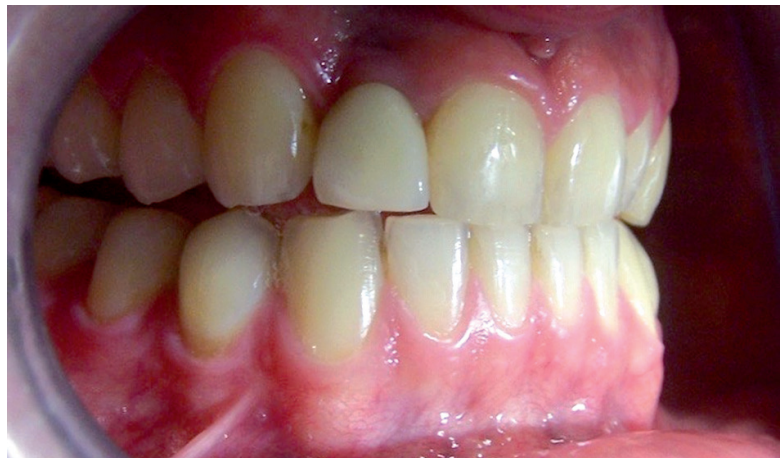

FIGURE 7. Visible atrophy of the alveolar bone in the neighborhood of tooth agenesis 12 


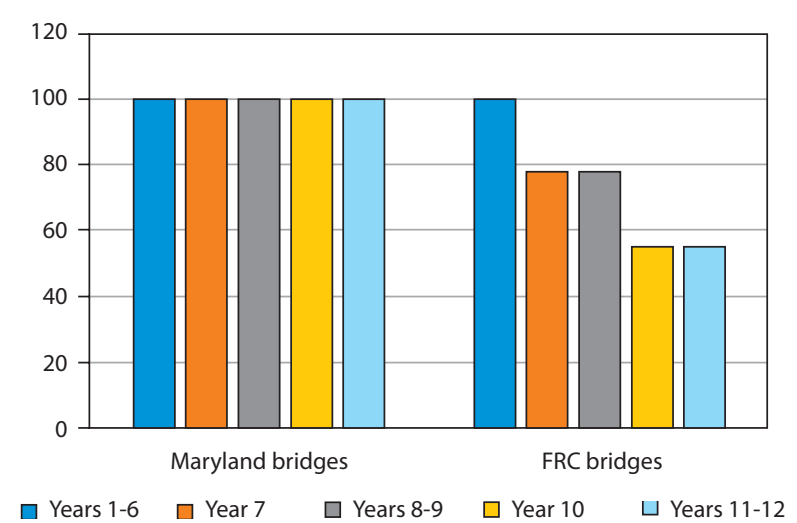

FIGURE 8. Evaluation of the effectiveness of Maryland and FRC bridges in the treatment of hypodontia of upper lateral incisors in adult patients in years 1-12

Based on digital radiological photography, it was found that under the bridge spans, at the place of the missing tooth, bone tissue atrophy occurs, which may cause aesthetic problems.

Patients treated with adhesive bridges declared $100 \%$ satisfaction with aesthetic and functional effects, although $15.38 \%$ reported complications and $23.07 \%$ reported problems with their use. Also, $100 \%$ of respondents declared compliance of the treatment effect with expectations, $84.61 \%$ of positively assessed repairs done. However, $15.38 \%$ of respondents would change the treatment method.

\section{DISCUSSION}

The treatment of hypodontia of the upper lateral incisors in adults is a difficult therapeutic challenge. When deciding on the treatment method, it is necessary to consider the restoration of oral function in accordance with the requirements of comfort and aesthetics, while maintaining the proper condition of the teeth surrounding the gap [2]. Many years of experience indicate that the best clinical effects are obtained after the application of the intraosseous implant and the protective crown [3]. When choosing the implant prosthetic procedure, the patient's age, coexisting dental occlusal defects, systemic diseases, preferences, and the economic status should be taken into account. In young patients and due to possible orthodontic recurrence, temporary restorations are used prior to implantation. At present, mainly adhesive restorations are made for this purpose, which have little or no invasiveness for the teeth surrounding the gap. In some cases, temporary bridges become long-term [16].

The study and literature data point to varying clinical effectiveness of adhesive bridges [16, 19-24].

Under the terms of the present study, an acceptable condition was noted in all cases during the first 6 years of observation. This is a better result than previously
TABLE 1. Results of the patient satisfaction survey 10 years after completing the additions

\begin{tabular}{|c|c|c|c|c|}
\hline \multirow{2}{*}{$\begin{array}{c}\text { Type } \\
\text { of reconstruction }\end{array}$} & \multirow{2}{*}{$\begin{array}{l}\text { Number } \\
\text { of patients }\end{array}$} & \multirow{2}{*}{$\begin{array}{l}\text { Number } \\
\text { of questions }\end{array}$} & \multicolumn{2}{|c|}{ Answer } \\
\hline & & & Yes & No \\
\hline \multirow{9}{*}{ Addition } & \multirow{9}{*}{13} & 1 & 2 & 11 \\
\hline & & 2 & 13 & 0 \\
\hline & & 3 & 11 & 2 \\
\hline & & 4 & 13 & 0 \\
\hline & & 5 & 3 & 10 \\
\hline & & 6 & 13 & 0 \\
\hline & & 7 & 11 & 1 \\
\hline & & 8 & 13 & 0 \\
\hline & & 9 & 2 & 11 \\
\hline
\end{tabular}

described. In the case of FRC bridges, other authors reported $91.3 \%$ of positive clinical effects after 2 years, $78.3 \%$ after 3 years [19], and $82.7 \%$ after 42 months [20]. The authors of above-mentioned studies reported that a relatively small percentage of damage to the bridges under assessment resulted from a very careful selection of patients, in whom all support zones were preserved.

A meta-analysis carried out by Alraheam et al. showed that adhesive bridges allow, over a 5-year observation period, clinical success of $88.18 \%$ for a metal framework and $84.41 \%$ for non-metal framework (including $92.07 \%$ of zirconium oxide), $94.26 \%$ of $\mathrm{Al}_{2} \mathrm{O}_{3}$, and $84.83 \%$ of FRC bridges), with a failure rate of $p>0.05$. Technical errors were indicated as the main cause of failures [21].

One case of polymer delamination found in the $7^{\text {th }}$ year of observation was a consequence of an error in the clinical procedure, while 2 cases resulted from probable occlusal overloads. One FRC bridge was made again and is still in use. However, in the second and subsequent 2 cases of loss of FRC bridge retention (in the $10^{\text {th }}$ year of observation), the therapeutic method was changed and traditional 3-point ceramic-metal bridges were made.

Under the conditions of the present study, the full clinical success was obtained after the application of adhesive bridges on a metal framework, which confirms previous reports [21-23], e.g. Botelho et al. found an acceptable clinical effect in $97 \%$ after 5 years, $91 \%$ after 10 years, and $84 \%$ after 15 years [22].

Other study showed $100 \%$ of clinical success after 6 years and $98.2 \%$ after 10 years using RBFDPs. Based on the research, it was found that this method achieves better results than traditional bridges or implants [24].

Good condition of the marginal periodontium was observed in nearly all evaluated adhesive bridges. In addition, patients maintained particularly good oral hygiene and they followed the instructions perfectly.

Despite the damage in some cases, adhesive restorations were highly rated by patients. When making ad- 
hesive restorations, it is necessary to inform the patient about the advantages and disadvantages of these constructions. They should not be performed on demanding patients as well as patients with oral hygiene problems. Also, adhesive bridges are not recommended for persons with parafunction $[20,22,25]$.

In the case of teeth with short clinical crowns with disturbed enamel structure, non-carious defects, or present fillings, the enamel surface for adhesive fixing is often too small to guarantee the adequate retention. Due to the above, the abutment teeth must have the right height to guarantee a large adhesive surface. The preparation of mineralized tissues should be deep enough to ensure that the thickness of the composite layer is at least $2 \mathrm{~mm}$, which will prevent the possibility of polymer rupture [26].

\section{CONCLUSIONS}

The results obtained indicate that adhesive bridges can be used as long-term restoration in the treatment of hypodontia of the upper lateral incisors. The conditions determining their application are the absence of carious lesions of the abutment teeth, a large adhesive surface within the enamel, and particularly good oral hygiene.

\section{CONFLICT OF INTEREST}

The authors declare no potential conflicts of interest with respect to the research, authorship, and/or publication of this article.

\section{References}

1. Al-Ani AH, Antoun JS, Thomson WM, Merriman TR, Farella M Hypodontia: an update on its etiology, classification, and clinical management. Biomed Res Int 2017; 2017: 9378325.

2. AlShahrani I, Togoo RA, Alqarni MA. A review of hypodontia: classification, prevalence, etiology, associated anomalies, clinical implications and treatment options. World J Dent 2013; 4: 117-125.

3. Hobkirk JA, Gill DS, Jones SP, et al. Hypodontia: a team approach to management. London: Wiley Blackwell; 2010.

4. King P, Maiorana C, Luthardt RG, et al. Clinical and radiographic evaluation of a small-diameter dental implant used for the restoration of patients with permanent tooth agenesis (hypodontia) in the maxillary lateral incisor and mandibular incisor regions: a 36-month follow-up. Int J Prosthodont 2016; 29: 147-153.

5. Romeo E, Lops D, Amorfini L, Chiapasco M, Ghisolfi M, Vogel G. Clinical and radiographic evaluation of small-diameter implants followed for 1-7 years. A longitudinal study. Clin Oral Implants Res 2006; 17: 139-148.

6. Schneider U, Moser L, Fornasetti M, Piattella M, Siciliani G. Esthetic evaluation of implants vs canine substitution in patients with congenitally missing maxillary lateral incisors: are there any new insights? Am J Orthod Dentofacial Orthop 2016; 150: 416-424.

7. Bernard JP, Schatz JP, Christou P, Besler U, Kiliaridis S. Long-term vertical changes of the anterior maxillary teeth adjacent to single implants in young and mature adults. A retrospective study. J Clin Periodontol 2004; 31: 1024-1028.

8. Thilander B, Odman J, Jemt T. Single implants in the upper incisor region and their relationship to the adjacent teeth. An 8-year followup study. Clin Oral Implants Res 1999; 10: 346-355.
9. Klimel K Die Zahnärztliche Preparationstechnik - Grundlagen Situationsanalyse - Arbeitskonzept. Dtsch Zahnärztl Z 1981; 36: 619-624.

10. Klotzer WT. Die traumatische Schädigung der Pulpa bei der Überkronung. Dtsch Zahnärztl Z 1984; 39: 791-794.

11. Schwickerath H. Das UDA - Ankersystem zur Versorgung kleiner Lücken. Dtsch Zahnärztl Z 1988; 43: 469-472.

12. Livaditis GJ, Thompson VP. Etched castings: an improved retentive mechanism for resin - bonded retainers. J Prosthet Dent 1982; 47: 52-58.

13. Livaditis GJ. Die Maryland-Brücke: Gestaltungsprinzipien. Int J Parodont Rest Zahnheilk 1983; 4: 34-36.

14. Hansson O, Moberg LE. Evaluation of three silicoating methods for resin-bonded prostheses. Dent Res 1993; 101: 243-251.

15. Kerschbauma T. Protetyka adhezyjna. Wrocław: Elsevier Urban \& Partner; 1999; 59-104.

16. Vinha LC, Kuga MC, Bandeca M, et al. Esthetic rehabilitation with composite resin in a patient with lateral incisor agenesis. Scient J Dent 2015; 2: 36-39.

17. Kern M. Mosty adhezyjne. Minimalnie inwazyjne - estetyczne trwałe. Warszawa: Quintessence Publishing Polska; 2018.

18. Kern M, Passia N, Sasse M, Yazigi Ch. Ten-year outcome of zirconia ceramic cantilever resin-bonded fixed dental prostheses and the influence of the reasons for missing incisors. J Dent 2017; 65: 51-55.

19. Uniu N, Belli S Three-year clinical evaluation of fiber-reinforced composite fixed partial dentures using prefabricated pontitics. J Adhes Dent 2006; 8: 183-186.

20. Pekka K, Vallitt U. Survival rate of resin-bonded, glass fiber-reinforced composite fixed partial dentures with a mean follow-up of 42 months: a pilot study. J Prosthet Dent 2004; 91: 241-245.

21. Alraheam IA, Nguyen Ngoc C, Weisen CA, Donovan TE. Fiveyear success rate of resin-bonded fixed partial dentures: a systematic review. J Esthet Restor Dent 2019; 31: 40-50.

22. Botelho MG, Chan AW, Leung NC, Lam WY. Long-term evaluation of cantilevered versus fixed-fixed resin-bonded fixed partial dentures for missing maxillary incisors. J Dent 2016; 45: 59-66.

23. Sasse M, Kern M. CAD/CAM single retainer zirconia-ceramic resin-bonded fixed dental prostheses: clinical outcome after 5 years. Int J Comput Dent 2013; 16: 109-116.

24. Kern M, Sasse M. Ten-year survival of anterior all-ceramic resin-bonded fixed dental prostheses. J Adhes Dent 2011; 13: 407-410.

25. Shastri D, Nagar A, Tandon P, Chugh V. Ortho-prostho management of hypodontia using fibre-reinforced composite resin bridge: an interdisciplinary approach. J Interdiscip Dent 2015; 5: 105-110.

26. Geissberger M. Esthetic Dentistry in Clinical Practice. Ames: WileyBlackwell; 2010. 